\title{
'Hongju': A Seedless Table Grape Cultivar
}

\author{
Jeong Ho Roh, Youn Young Hur ${ }^{1}$, Sung Min Jung, and Kyo Sun Park \\ Fruit Research Division, National Institute of Horticultural \& Herbal \\ Science, Wanju 55365, Korea
}

\section{Hae Keun Yun \\ Department of Horticulture and Life Science, Yeungnam University, Gyeongsan 38541, Korea}

\section{Jong Chul Nam, Hae Sung Hwang, Dong Jun Im, and Kyong Ho Chung Fruit Research Division, National Institute of Horticultural \& Herbal Science, Wanju 55365, Korea}

Additional index words. Vitis vinifera, breeding, seedless

'Hongju' is a seedless table grape developed by the Rural Development Administration (RDA) grape breeding program in Korea. With increasing imports of table grapes from Chile and the United States, Korean consumers largely prefer seedless table grapes with nonslip skins (Heo and Park, 2017). 'Hongju' is a new cultivar that meets current consumer demands. 'Hongju' has red berries with firm flesh, nonslip skin, and a slight Muscat flavor. The mean berry weight is $5.4 \mathrm{~g}$ without gibberellin application. 'Hongju' grapes can be stored for up to 3 months after harvest under suitable conditions, which makes them attractive for export markets.

\section{Origin}

'Hongju' is derived from a cross between 'Italia' and 'Perlon', which was performed in 1996 at the National Institute of Horticultural and Herbal Science, RDA, Wanju, Korea (Fig. 1). It was selected preliminarily in 2006 and tested as 'Wonkyo RA-34' in seven different locations (Suwon, lat. $37^{\circ} 16^{\prime} \mathrm{N}$, long. $127^{\circ} 02^{\prime} \mathrm{E}$; Chuncheon, lat. $37^{\circ} 53^{\prime} \mathrm{N}$, long. $127^{\circ} 44^{\prime} \mathrm{E}$; Yesan, lat. $36^{\circ} 41^{\prime} \mathrm{N}$, long. $126^{\circ} 51^{\prime} \mathrm{E} ; \quad$ Okcheon, lat. $36^{\circ} 20^{\prime} \mathrm{N}$, long. $127^{\circ} 45^{\prime} \mathrm{E}$; Iksan, lat. $35^{\circ} 56^{\prime} \mathrm{N}$, long. $126^{\circ} 59^{\prime} \mathrm{E}$; Jinju, lat. $35^{\circ} 11^{\prime} \mathrm{N}$, long. $128^{\circ} 06^{\prime} \mathrm{E}$; and Naju, lat. $35^{\circ} 01^{\prime} \mathrm{N}$, long. $126^{\circ} 43^{\prime} \mathrm{E}$ ). Ownrooted vines were planted in five random plots for each site, and fruit production and vine quality were evaluated from 2008 to 2013.

Received for publication 10 July 2018. Accepted for publication 27 Sept. 2018

This work was supported by a grant from the Research Project for Agricultural Science \& Technology Development (PJ01272901), Rural Development Administration, Wanju, Korea.

${ }^{1}$ Corresponding author. E-mail: yyhur76@korea. $\mathrm{kr}$.

This is an open access article distributed under the CC BY-NC-ND license (https://creativecommons. org/licenses/by-nc-nd/4.0/).
After evaluation, we named this cultivar Hongju in 2013.

\section{Description and Performance}

Vines were trained to a modified T-trellis (3-m single arm), and 27 shoots per vine were maintained by spur pruning. Vines were spaced $3 \mathrm{~m}$ by $3 \mathrm{~m}$ apart, which provided a vineyard density of 1000 vines/ha. We used standard table grape cultural practices such as annual dormant pruning, mechanical weed control, and drip irrigation. Annual fruit evaluation data collected from 'Hongju', 'Italia', and 'Campbell Early' grapevines from 2011 to 2013 in Suwon, Korea, included vine yield, cluster characteristics, and berry weight. 'Italia' is the female parent of 'Hongju', and 'Campbell Early' is the most widely used grape cultivar in Korea. Both cultivars are seeded. We estimated berry weight based on 50 samples collected from five different vines, with two clusters taken from each vine and five

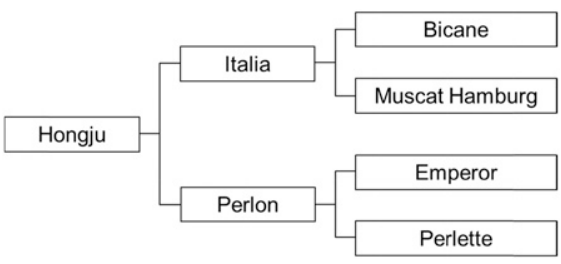

Fig. 1. Pedigree of 'Hongju' seedless table grape cultivar. berries collected from each cluster. We also used those samples to determine juice soluble solids and titratable acidity. The average values reported for various characteristics were based on data collected from five replicate vines during each harvest year.

Flowers. Flowers of 'Hongju' are perfect and self-fertile, blooming late in the season (on 8 June in Suwon, Korea) after late-season budbreak (3 May).

Berry characteristics. 'Hongju' berries are seedless. Residual seed traces are barely discernible as a result of the firm texture of the flesh. The berry skin is of medium thickness and adheres to the flesh. The berries are round or slightly ovate in shape and are large, with an average weight of $5.4 \mathrm{~g}$ even without gibberellin application (Table 1) These characteristics are desirable in seedless berries. 'Hongju' berries are similar in weight to seeded 'Campbell Early' berries and weigh less than seeded 'Italia' berries. The grapes have a light Muscat flavor when fully ripe. 'Hongju' ripens between 25 Sept. and 2 Oct. in Suwon, Korea, about $28 \mathrm{~d}$ later than 'Campbell Early' and $10 \mathrm{~d}$ later than 'Italia'. The average total soluble solids content of 'Hongju' berries is $18.4{ }^{\circ} \mathrm{Brix}$, which is similar to that of 'Italia' and greater than that of 'Campbell Early' berries. In contrast,

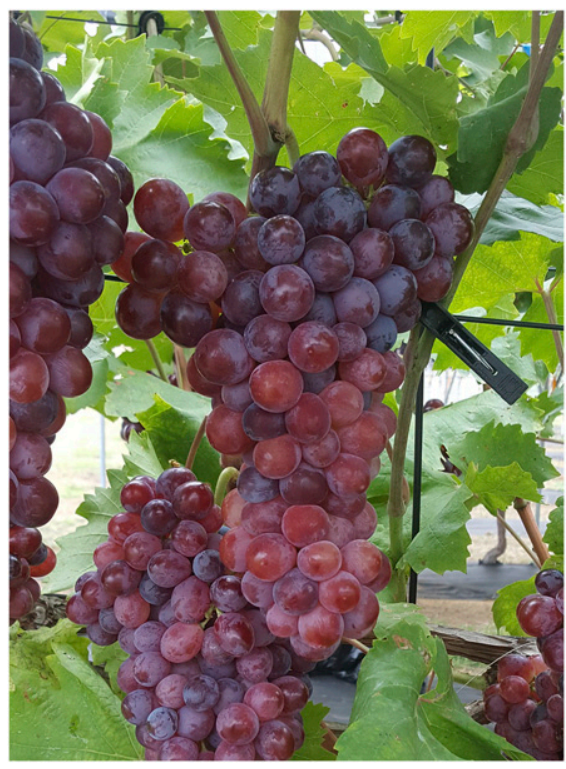

Fig. 2. Clusters of 'Hongju' seedless table grape cultivar.

Table 1. Characteristics of 'Hongju' seedless table grape cultivar and other cultivars grown in Suwon, Korea, from 2011 to 2013.

\begin{tabular}{|c|c|c|c|c|c|c|c|}
\hline Cultivar & $\begin{array}{c}\text { Harvest } \\
\text { date }\end{array}$ & $\begin{array}{l}\text { Seed } \\
\text { status }\end{array}$ & Cluster wt (g) & Berry wt (g) & $\begin{array}{l}\text { Soluble } \\
\text { solids } \\
\text { content } \\
\left({ }^{\circ} \text { Brix }\right)\end{array}$ & $\begin{array}{c}\text { Titratable } \\
\text { acidity }(\%)^{z}\end{array}$ & Yield/vine $(\mathrm{kg})$ \\
\hline Hongju & 1 Oct. & Seedless & $538.2 \pm 21.4^{y}$ & $5.4 \pm 0.3$ & $18.4 \pm 0.3$ & $0.57 \pm 0.04$ & $21.7 \pm 0.6$ \\
\hline Italia & 20 Sept. & Seeded & $462.7 \pm 39.3$ & $6.6 \pm 0.4$ & $18.5 \pm 0.3$ & $0.46 \pm 0.05$ & $18.5 \pm 0.8$ \\
\hline Campbell Early & 2 Sept. & Seeded & $370.1 \pm 30.5$ & $5.3 \pm 0.3$ & $16.0 \pm 0.2$ & $0.59 \pm 0.03$ & $21.2 \pm 1.6$ \\
\hline
\end{tabular}

${ }^{\mathrm{z}}$ Volume percent tartaric acid.

${ }^{\mathrm{y}}$ Mean $\pm \mathrm{SD}$ 
'Hongju' berry acidity is $0.57 \%$, which is greater than that of 'Italia' and similar to that of 'Campbell Early' berries. The balance between sweetness and acidity enhances the taste of 'Hongju' grapes.

Cluster characteristics. The average cluster weight of 'Hongju' is $538.2 \mathrm{~g}$. The clusters are conical in shape, sometimes shouldered, and tight in berry setting (Fig. 2). Uniform shape and red skin color of the berries render excellent cluster appearance. We observed minimal berry shattering and cracking during storage and transportation after harvest. These characteristics increase the marketability of 'Hongju' grapes. The fruit productivity of 'Hongju' from 6-year-old trees was $\approx 21.7$ tons/ha. In comparison, 'Italia' and 'Campbell Early' show a fruit productivity of $\approx 18.5$ tons/ha and 21.2 tons/ha, respectively.

Vine characteristics. Own-rooted vines show vigorous growth. Vines have a uniform cluster size and ripening period, and excellent berry setting as a result of spur pruning. The foliage is moderately susceptible to downy mildew (Plasmopara viticola Berl. $\&$ de Toni). However, we did not observe powdery mildew (Erysiphe necator Schw.) on the vines during the cultivation period.

\section{Availability}

'Hongju' has been registered at the Korea Seed \& Variety Service. A patent application has been submitted to the U.S. Patent and Trademark Office under the name 'Hongju'.

\section{Literature Cited}

Heo, J.Y. and S.M. Park. 2017. 'Sujeong': A green seedless table grape cultivar. HortScience 52:463-464. 